\title{
FIELD INVESTIGATION OF THE RELATIONSHIP BETWEEN BATTERY SIZE AND PV SYSTEM PERFORMANCE
}

John Stevens, Jay Kratochvil

Sandia National Laboratories

\author{
Steve Harrington \\ K-Tech Corporation
}

\begin{abstract}
Four photovoltaic-powered lighting systems were installed in a National Forest Service campground in June of 1991 . These systems have identical arrays, loads and charge controllers. The only difference was in the rated capacity of the battery bank for each system. The battery banks all use the same basic battery as a building block with the four systems utilizing either one battery, two batteries, three batteries or four batteries. The purpose of the experiment is to examine the effect of the various battery sizes on the ability of the system to charge the battery, energy avaliable to the load, and battery lifetime. Results show an important trend in system performance conceming the impact of charge controllers on the relation between array size and battery size which results in an inability to achieve the days of battery storage originally designed for.
\end{abstract}

\section{INTRODUCTION}

This experiment was designed to examine the issue of battery size relative to array and load size given a specific charge controller. During the experiment a trend appeared conceming the ability of the PV array to charge the battery. That is, a battery which was unable to maintain the load on a given night (indicating the battery was not fully charged) only accepted a fraction of the solar energy available the next day. This resulted in the load tuming off prematurely every night when, theoretically, there was ample daytime energy to run the load all night long. This paper examines this issue of a battery not accepting the array energy and the relationship between this problem and battery to array ratio. There are secondary effects such as seasonal variations in battery temperature and in array current which will have an impact on system performance. These effects are not discussed in this paper as their impact is negligible in comparison to the main point.

\section{EXPERIMENTAL SETUP}

Four PV lighting systems were installed which were as near as possible to identical in every respect except battery bank size. These systems were installed at a National Forest Service campground near Abuquerque. This beation provided lower insolation than Albuquerque (which exereised the betteries), allowed the local foreat Service employoes to observe its

*This work is supported by the Photovoltaic Energy Technology Division of the United States Department of Energy, Contract DE AC0476DP00789 performance, and was an easily accessible location. This particular campground is in an area which gets significantly less insolation than Albuquerque. The campground is near a ranger station and receives weekly ranger visits in the summer and is lese than thity minute drive from Sandia's offices.

The systems were purchased and installed in June of 1991 by a local electrical contractor. Each system is a pre-assembled package, from a well known photovoltaic supplier, which the contractor bought at an electrical supply house. All components were the supplier's standard components with the battery size being the only exception. Each system consisted of one 18-watt low-pressure sodium lamp, two 48-watt modules, a combination charge controller/lighting controller and the batteries. The manufacturer's literature for the lights lists these as a 2.3 amp bad. Their operational current has been 1.9 amps since the date they were installed. The two modules connected in parallel supply about 5.7 amps at atandard test conditions. The charge controlling scheme is the on-off shunting type which either applies full array current to the battery or short-cincuits the array, depending on battery voltage. The batteries were all placed in large plastic tool boxes of the type that are used in the back of pickup trucks, and these boxes were installed below ground level for temperature moderation. The top of the plastic tool box was then framed and covered by a sheet of plywood. The batteries are U. S. Batteries BA12-105, rated at 12 volts and 105 amp-hours (20 hour rate) and are flooded lead-acid deep-cycle batteries. The systems have either one battery, two, three or four batteries. This is roughly equivalent to 3 days, 6 days, 9 days and 12 days storage at $25^{\circ} \mathrm{C}$ based on a daily load of 22 amp-hours and having $65 \%$ of the battery capacity available before low-voltage disconnect.

\section{SYSTEM NOTES}

Each of the controllers was bench tested at Sandia to determine setpoints prior to installation. The controllers all had the same setpoints. The high-voltage disconnect was 14.5 volts and was cemperature compensated. The reconnect voltage was 13.4 volts. Low-voltage disconnect was 11.75 with low-voltage reconnect at 12.4 volts (all measurod at $25^{\circ} \mathrm{C}$ ). A battery discharge curve was eatablished using a control battery (four additional betteries were purchased as controls for laboratory texting to examine any anomolies that occurred) using a $1.9 \mathrm{amp}$ load. This was used to determine what capacity was available before the low-voltage disconnect (LVD) removed the load from the battery. This showed that about 65 amp-hours (about $62 \%$ of the battery rated capacity) were available per battery before 


\section{DISCLAIMER}

Portions of this document may be illegible electronic image products. Images are produced from the best available original document. 
LVD.

The 1.9 amp lighting load runs from dusk to dawn (as sensed by the controller from array voltage) every day of the year. This results in a load of roughly 22 amp-hours per night in the winter. This implies that a minimum of 25 amp-hours per day are required in the winter for recharging. (This is an estimate based on energy replacement, battery losses and average monthly insolation.) The original design assumptions indicate that this amount of energy is available. That is, 5.7 amps for 4.7 hours per day, or 26.8 amp-hours per day in winter.

With a 22 amp-hour nightly load, the 65 amp-hour available capacity per battery is roughly a three-day battery. Also, 22 amp-hours daily discharge is roughly $20 \%$ of the battery's 105 amp-hour rated capacity resulting in a $20 \%$ daily depth of discharge. Both of these values make the three-day (single) buttery appear to be an appropriate choice.

\section{An Aside on Insolation}

This project stressed one of the basic problems with PV system design - - insolation estimation. In order to arrive at an estimate of the insolation for this site, Albuquerque data was used and reduced by one sun-hour per day to account for the mountain area micro climate. Albuquerque winter average insolation is 5.7 sun-hours per day. This lead to an estimate of 4.7 sunhours per day in winter. Two winters of actual data

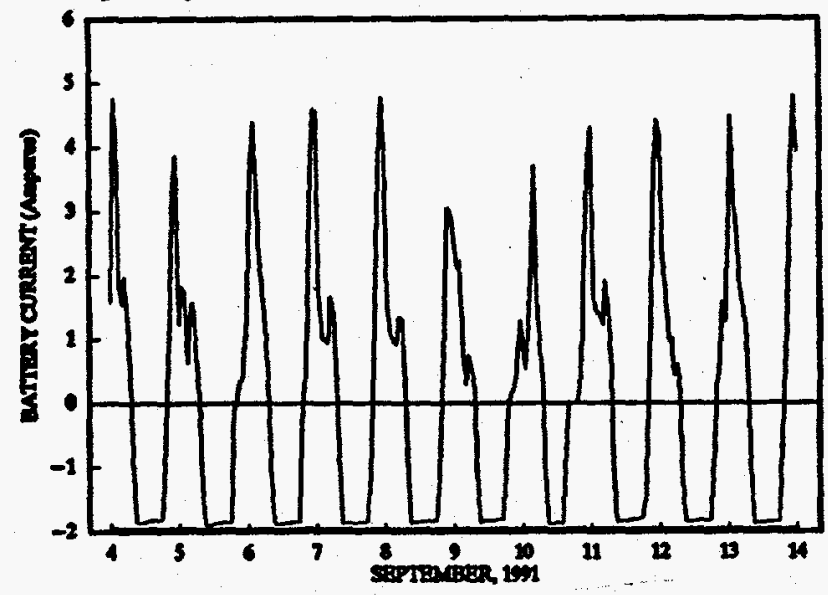

Figure 1. Battery current, 1 battery system, Sept. 1991, showing failure to maintain load during the night of Sept. 10-11. Comparison of current curve for Sept. 7 and 8 with insolation curve in figure 2, shows that the controller was regulating energy flow, apparently indicating a fully charged battery.

show - December average of 3.4 sun-hours per day, significantiy less than expected. This stresses the difficulty in extimating insolution, but does not affect this experiment as the LVD protects the batteries from over-discharge and the instrumentation allows monitoring the details of energy flow which is necessary for understanding system operation.

\section{FIELD RESULTS}

Figure 1 shows the system current during a period in
September, 1991. Positive current is from the array to the battery and negative current is from the battery to the load. It can be seen that on the night of September 10, the light was curned off prematurely by the low-voltage disconnect. This was the first time this happened since the system was installed. This only happened with the one battery system, the others all performed as they should have during this period. Figure 2 shows insolation during this period. Note that September 7 and 8 were good sun days with over 7 sun-hours per day. Also note the shape of the array to battery current curve for these days on figure 1. The midday dip and lateday increase on the two good sun days is an important array utilization factor which will be discussed later. Table 1 shows energy flow in three of the systems. The four battery system is left out of most of these tables for convenience in presentation and because it paralleled the three battery system in most instances.) None of the systems accepted the full energy available from the array (7 sunhours $\times 5.7$ amps $=40$ amp-hours) implying that they are all fully charged. It will be shown later that this was not the case. The control strategy simply was not allowing the batteries to receive the array energy. Note that the one battery system had two days of limiting the input to about 22 amp-hours per day, followed by a 17.8Ah day and then a 13.5Ah day. On both of these days, the nightly output was restricted to roughly what the associated daily input had been. In other words, there was not three days of storage;

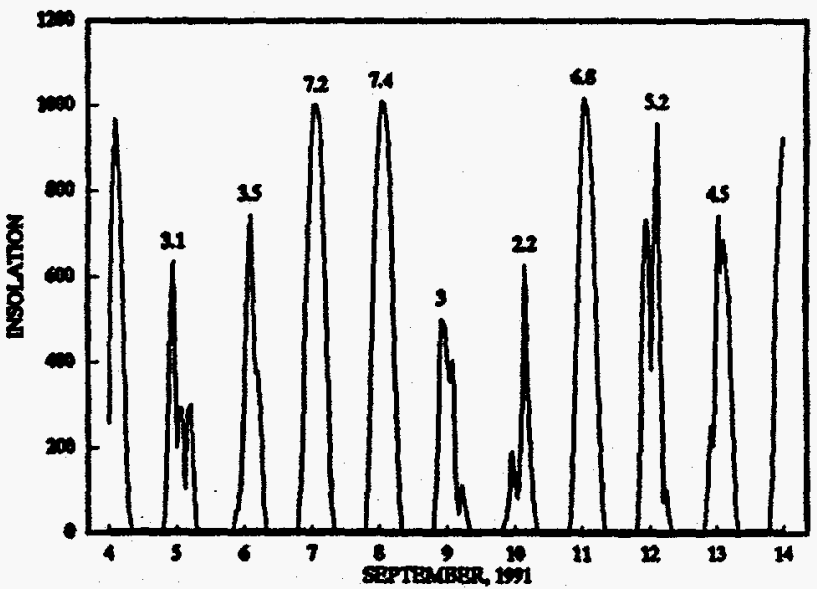

Figure 2. Insolation, Sept. 1991 (sun-hours per day shown)

\begin{tabular}{|c|c|c|c|c|c|c|}
\hline $15 P / 91$ & $m^{2}-2 n$ & $\begin{array}{l}\text { THARY } \\
\text { Mh-out }\end{array}$ & $\begin{array}{c}2 \text { Bnz } \\
n_{h}-\ln \end{array}$ & $\begin{array}{l}\text { PRI } \\
\text { Nh-out }\end{array}$ & $\begin{array}{r}3 \mathrm{~m} \\
\mathrm{n}^{2}-\ln \end{array}$ & WhI \\
\hline $\begin{array}{r}7 \\
8 \\
90\end{array}$ & $\begin{array}{l}22.2 \\
32.1 \\
27.8 \\
23.5 \\
21.7\end{array}$ & $\begin{array}{l}20.5 \\
20.2 \\
18.6 \\
13.3 \\
20.7\end{array}$ & $\begin{array}{l}27.1 \\
24.4 \\
26.2 \\
25.3 \\
32.1\end{array}$ & $\begin{array}{r}21.2 \\
20.7 \\
22.3 \\
21.8 \\
21\end{array}$ & $\begin{array}{l}26.2 \\
23.7 \\
14.2 \\
16.6 \\
32.1\end{array}$ & \\
\hline
\end{tabular}

Table 1. Energy flow , Sept. 1991

there wasn't even one day of storage. The two and three battery systems did have enough storage to maintain the load during this period. Note also that the day following these two bad days, the one-battery system only accepted 21.7Ah, even though it had gone into low-voltage disconnect, indicating a shortfall of some 65 amp-hours, and there were about 40 amp-hours available from the array. Also note that the two- and three-battery systems accepted over thirty amp-hours following the two bad days while the onc-battery system was receiving less than 22Ah. 
At this point it might be assumed that there is a problem with the battery in the one-battery system. It will be shown later that the problem is in control strategy, not in the battery.

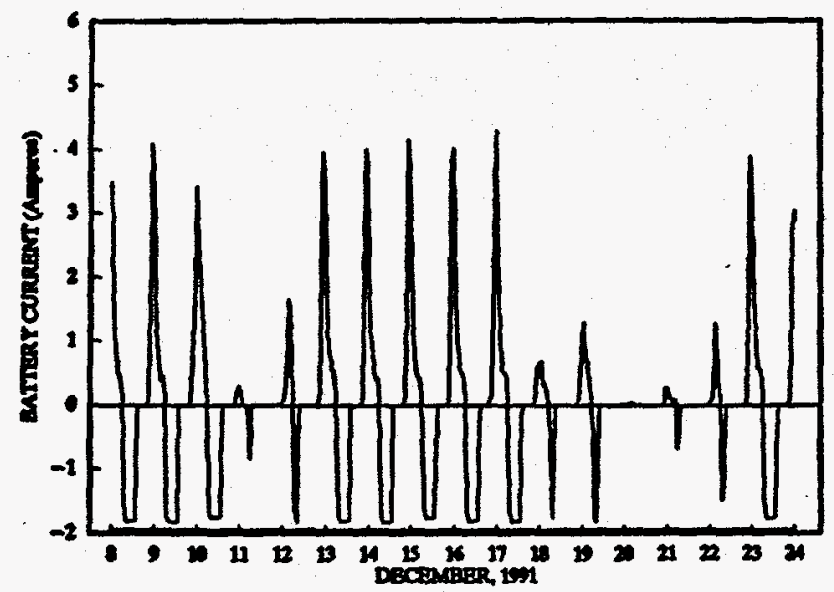

Figure 3. Battery current, 1 battery system, Dec. 1991, showing daily regulation yet daily failure to carry the load.

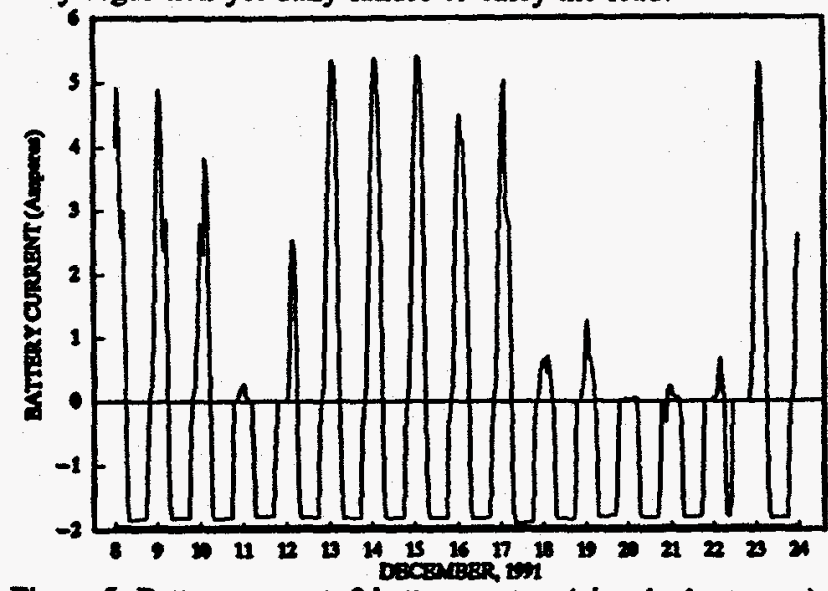

Figure 5. Battery current, 3 battery system (nine day's storage), Dec. 1991, showing failure to carry the load after five bad days. The input current curve shape indicates that regulation occurred on Dec. 17.

Figures 3, 4 and 5 show the one, two- and three-battery systems in December. Notice that during this period the light is never on all night for the one-battery system, it goes off after two bad days on the two battery system and it goes off after five bad days on the three battery system. Ambient and battery temperatures were monitored as part of the data acquisition system. The battery temperatures never got below $5^{\circ} \mathrm{C}$, and displayed a diumal cycle of decreasing temperature all night and increasing temperature all day, except on very bw insolation days, when the temperature never increased. If the battery operated continually at $5^{\circ} \mathrm{C}$, it would result in a $20 \%$ roduction of capacity, based on roughly $1 \%$ decrease in capacity per degree C. Since $5^{\circ} \mathrm{C}$ is a minimum, it can be assumed that the batteries had greater than $80 \%$ capacity even on the worat days.

Figure 6 shows insolation during this period. Note that there were five good days with insolation between five and six sunhours each day preceding the poor weather. That means between 28 and 34 amp-hours were available to the systems each day. Table 2 shows energy flow for the systems during this time period. Note that the one-battery system only accepted roughly one half of the available energy, and only kept the light on for half the night. The two- and three-battery systems took advantage of most of the array energy, although both of them accepted less on the 17th than they had on the 16th, implying that they were fully charged. This would imply that these systems could carry the load for six and nine days respectively at this point. In fact, they carried the load for two and five days.

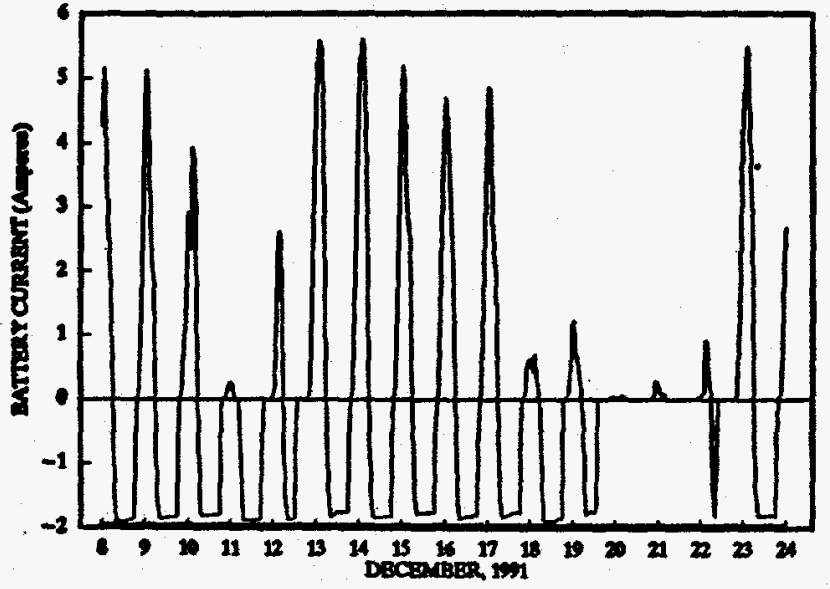

Figure 4. Battery current, 2 battery system (six day's storage), Dec. 1991, showing failure to carry load after two bad days.

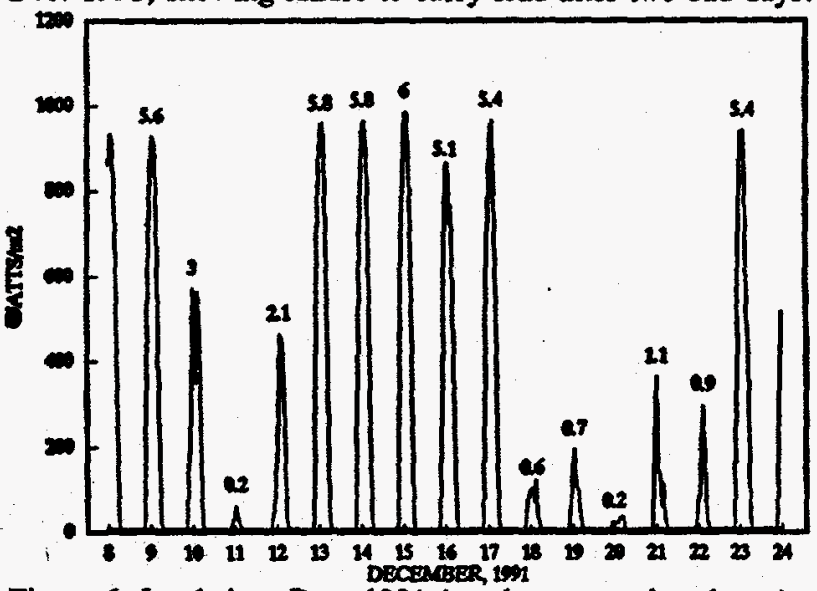

Figure 6. Insolation, Dec. 1991 (sun-hours per day shown)

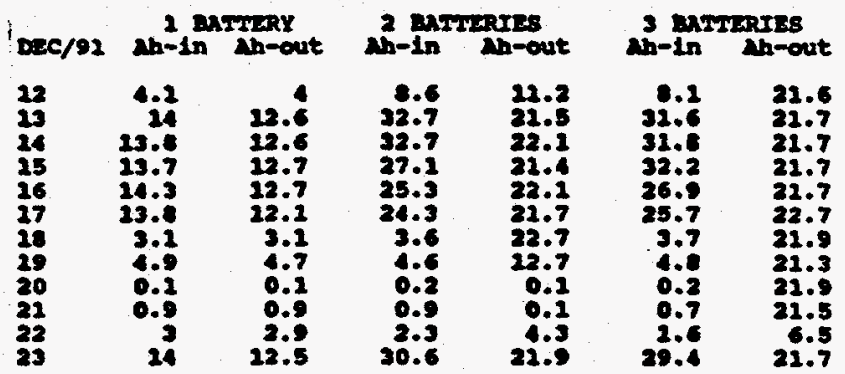

Table 2. Energy flow, Dec. 1991

These field results have been consistent over the one and onehalf years of data gathered from these systems. During the period of mid-April to mid-September, the lights run all night every night. During the remainder of the year, they are off for 
various amounts of time depending on weather. In all cases of the lights being out, it appears as if there isn't as much battery capacity installed as the design indicates. That is, the amount of energy available to the loads after a time when the battery won't accept further charge is a fraction of what the battery rated capacity indicates it should be. On the surface, this indicates that the batteries have suffered some loss of capacity, but further testing showed that this wasn't the case. The problem was in the method for regulating energy flow to the battery.

\section{LABORATORY TESTS}

After one and one half years in the field, batteries from each system were brought into the lab for capacity testing in January of 1993. Each of the batteries was discharged initially to determine its state of charge as retrieved from the field. None of the batteries were expected to be well charged because they were removed early in the day during the winter. All laboratory tests were performed at $25^{\circ} \mathrm{C}$.

At the time the batteries were removed from the field, it was discovered that the two-battery system had a failed light. There had been no load on this system for two months, so it was expected that these batteries would be fully charged. The discharge test only showed 68 amp-hours per battery. Subsequent charge and discharge testing (on laboratory charger, not an array) showed these batteries to have full capacity of nearly 100Ah. (None of the tests resulted in the full rated $105 \mathrm{Ah}$, but most got very close once the battery had been cycled a few times.) Again, while in the field with no load, the energy was available to fully charge the battery. The battery was capable of accepting that charge, but it wasn't being charged. It will be shown that this is because of the combination of array size and charging strategy.

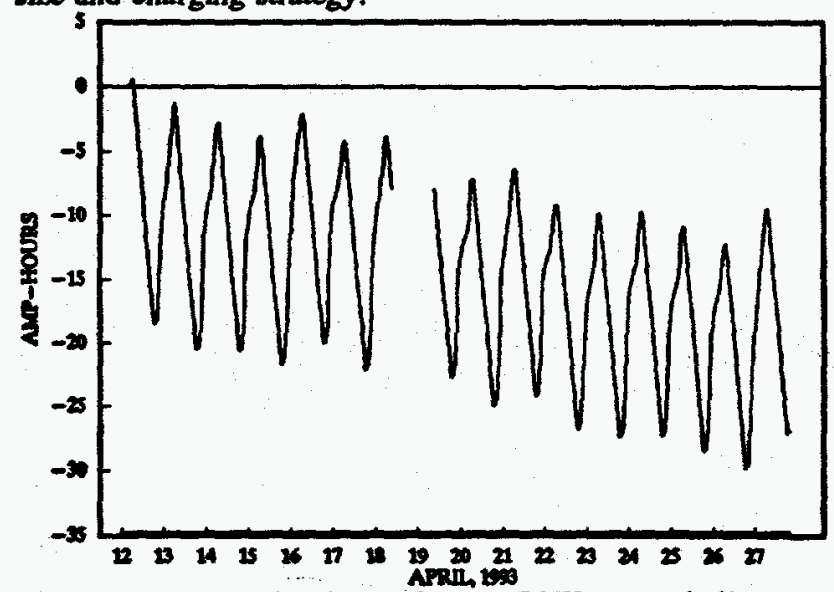

Figure 7. Accumulated amp-hourn, PSEL test timilar to 1 buttery system. Note continually decreasing capacity.

All of the butteries appeared normal in this discharge/recharge testing except the one-battery system battery which failed. An autopsy was performed at Sandia's Storage Batteries Department research facilities. Examination of the battery revealed large quantities of shed plate material on the positive plates, creating a buildup of this material half-way up the positive plates. This builup created a "soft short" between cell plates in each cell group. Specific gravities were taken from individual cells which also supported the existence of shorted plates. These findings were nearly identical through all cell groups in this battery. This indicates there was not a single cell failure, but excessive time spent at a low state of charge and inadequate overcharging to mix electrolyte [1]. Plate samples were sent to the battery manufacturer who confirmed our findings by stating that the battery had been "over discharged and inadequately rocharged". Additionally, photos of the disassembled battery were sent to an independent battery manufacturer who concurred with these findings.

After the charge/discharge tests showed that the batteries were capable of being fully charged (with the notable exception of the battery from the one-battery system), a series of teats was performed using the contral batteries to determine why the batteries were not being charged. These tests were performed at Sandia's Photovoltaic Systems Evaluation Laboratory (PSEL), and are ongoing.

\section{PSEL TESTING}

All PSEL testing was done with batteries at $25^{\circ} \mathrm{C}$. One of the control batteries was set up in the PSEL on an array with a similar output to those in the field test. This system was equipped with an identical charge controller to those in the field and a $1.9 \mathrm{amp}$ load which was switched on each night and off each morning. The battery for this test was fully charged prior to being installed in the test system. Current flow and voltage were then monitored on this system. In addition, a "flag" was established to indicate whether or not the controller was in the "charging" or "shunting" mode. In this system, data is sampled every second and stored as ten minute averages. The ten minute storage of the "flags" indicates array "on" and "off" time by toring the sum of the "charging" flags and the sum of the "shunting" flags. By observing the changes in the "on" and "off" times during a day, one can not only see how well the battery is being charged, but also see at what value of array current the battery can take full current versus partial current.

Figure 7 shows accumulated amp-hours for this system. (The gap on April 19 is due to a datalogging glitch.) An upward sloping curve indicates energy into the battery and a downward sloping curve indicates energy out of the battery. As can be scen, the battery has suffered an energy shortfall, both on an overall basis and on most days, since this test began. During this time period, the daily energy available from the array varied between 36 and $42 \mathrm{Ah}$, yet the battery only accepted an average of 17.2Ah while providing an average of 17.9Ah to the lond.

The test was ended after two weeks on the moming of April 28. The battery was then discharged to confirm that the capacity remaining was as indicated by the data. This discharge test showed remaining capacity of $65 \mathrm{Ah}$ which, when added to the 25Ah shown on the moming of the 28th, equals 90Ah. Actually, the amp-hour capacity indicated by the data is always a little high as the energy required to make up losses is included in this data. Therefore, the 25Ah shown on the moming of the 28th could easily have indicated a battery capacity that was 30 
to $35 \mathrm{Ah}$ Jow, which agrees with the 95 to $100 \mathrm{Ah}$ capacity this battery normally exhibits.

Note also from figure 7 that in midday on most days the input current is reduced for a time, then increases again. This is shown more clearly in figure 8 which is a "zoom" into April 15 and 16 from figure 7. Typically the current reduction begins around 10:30am for this system. Current flow then increases again around $5: 00 \mathrm{pm}$ for this system. It is apparent that the battery needs the energy available in midday (this is the maximum energy available which PV system designers count on for charging their batteries!) yet it is not used. Later in the day, so the available current is reduced, the battery is able to accept it. For this particular system, on April 26 the battery only accepted $10 \%$ of the energy available from the array between 11:00am and 3:00pm standard time, while accepting 100\% of the energy between 4:00pm (when array current fell below 2.5 amps) and sunset at 6:20.

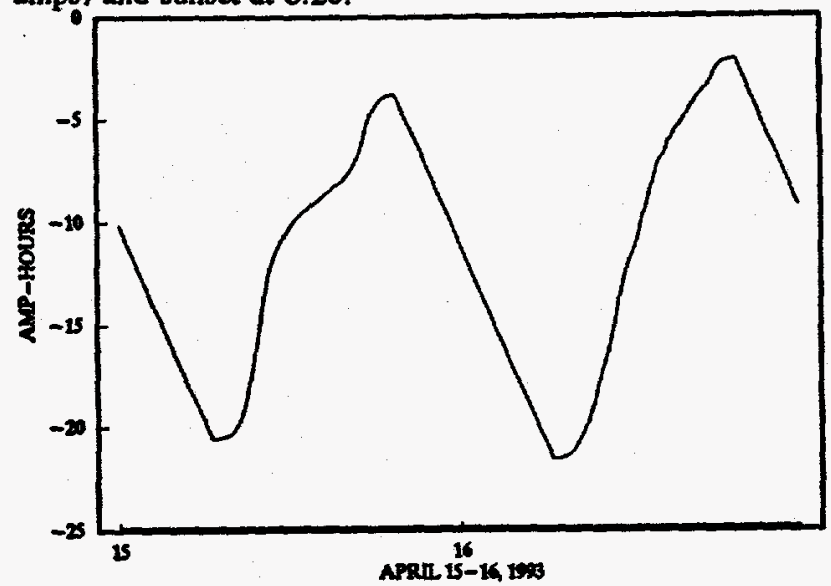

Figure 8. Battery current is reduced at midday on the full-sun day of April 15, but not on the poor-sun day of April 16, resulting in greater energy storage on the poor-sun day.

Another important trend can be noted by comparing April 15 and 16. On the 15th, the battery received 16.7Ah, and on the 16 th it received 19.4Ah. However, on the 15th there were 7.6 sun-hours and on the 16 th there were only 4.3 . The reduced insolation from the "bad" day resulted in lower array currents which the battery was able to accept, resulting in greater energy storage.

This failure to accept full array energy is the result of the battery internal resistance and the array current working at odds with each other. The charge controller is monitoring battery terminal voltage to determine whether or not the battery is charged. As the buttery sits at rest (controller in the "of" mode), the terminal voltage falls low enough that the controller switches into the "on" mode to charge the battery. This allows full array current to the battery. This current and the battery internal resistance result in a voltage rise at the battery terminals. If the current is sufficiently high, the resulting voltage rise is adequate to immediately send the controller into the "off" mode. As seen from the April 26 data quoted above, the "off" time can be $90 \%$ of the total time for sufficiently high current. The current needn't be "obviously" high for this to be the case as demonstrated by the 5.7 amp array feoding a 100Ah battery.

This process of charging in the early and late part of the day when current is low while rejecting midday energy is what results in the input current curve shape first mentioned in association with figure 1 . In fact, this curve shape is apparent to come degree in many of the figures in this paper. Examination of figure 5 (the three battery system) shows that on December 13, 14 and 15 the current shape closely follows the insolation shape, while on Docember 17 there is a "ecoop" cut out from midday to later in the afternoon. This is a result of the battery accepting full array energy on the first three days, but the controller regulating energy flow during the high energy part of the last day. Notice that the battery in figure 3 (the onebattery system) shows this regulation effect on the 13th, 14th and 15th, even though it obviously was not fully charged as it only maintained the load for about half the night.

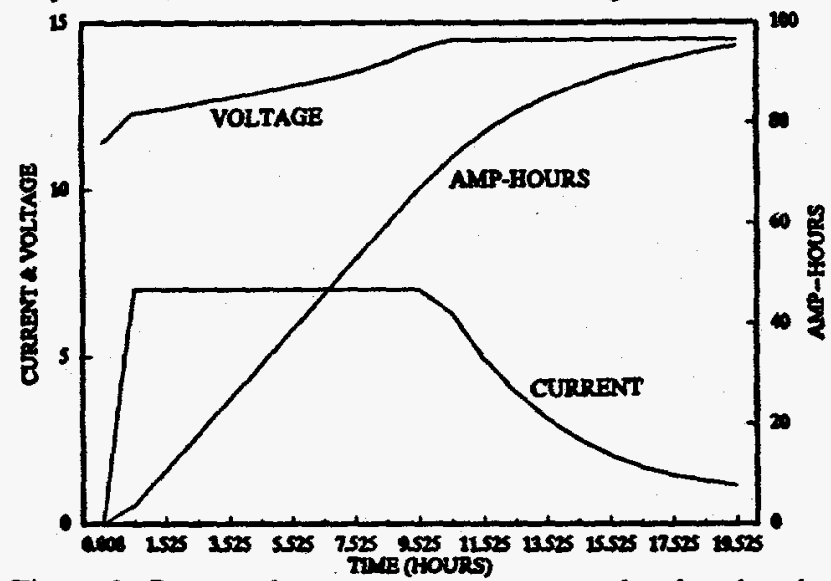

Figure 9. Battery charge acceptance curve, showing that the battery cannot accept 5 amps charging current without going above $\mathbf{1 4 . 5}$ volts whenever above $80 \%$ state of charge.

Figure 9 illustrates the relation between battery state of charge and acceptable charging current. This figure was generated by charging the control battery used in the PSEL tests from a fully discharged state. This was done on a computer controlled charger, not an array. The charger was set to deliver 7 amps until the battery terminal voltage reached 14.5 volts, at which time the charger switched to a constant voltage mode, delivering the current necessary to maintain 14.5 volts. It is important to stress that this curve is accurate for the specific battery desion being tested and that it only applies to a float voltage of 14.5 yolts. It can be seen from the sccumulated amp-hours that at about 75Ah the battery could no longer accept 7 amps without exceeding 14.5 volts, so the current was reduced. At $80 \mathrm{Ah}$ the current must be reduced below 5 amps. This implien that most two-module crystalline silicon PV arrays cannot charge this buttery in full sun above about $80 \%$ capacity with an "on-off" controller using 14.5 volt high-voltage setpoint.

\section{DISCUSSION OF RESULTS}

This set of experiments indicates that, at least for the combination of battery, controller and setpoint used in this test, increasing array size to account for unknowns in insolation without an associated increase in battery size is an error which 
will actually decrease the amount of energy stored in the battery. With the specific hardware used in this test, a charge rate greater than $\mathrm{C} / 20$ (that is, battery capacity divided by 20 equals charging current), resulted in sufficient voltage rise at the battery terminals that charging was prematurely terminated. Raising the high-voltage setpoint to a value near 14.8 may compensate for this when on-off controllers are used with charge rates of $\mathrm{C} / 20$ or greater. This will be invertigated in future work. Although full current is accepted when using a charge rate of $\mathrm{C} / 50$, this may be to far to $\mathrm{go}$ in compensating for the battery terminal voltage rise, as this may result in an extended time required to recharge the battery after a deep discharge, resulting in battery sulfation. A charge rate between $\mathrm{C} / 25$ and $\mathrm{C} / 50$, as in the two- and throo-battery systems seems to be appropriate. Adjustments in high-voltage regulation retpoint may still be needed at these ratios.

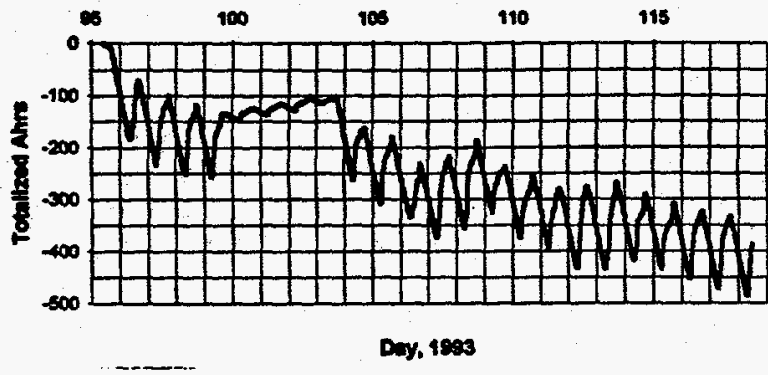

Figure 10. Accumulated amp-hours, 2600Ah sealed battery, showing reduction in battery capacity. The increase from day 100 to 103 was when there was no load on the system.

\section{OTHER SYSTEMS}

Since the inability to maintain a system in full state of charge was first uncovered as illustrated in figure 7, other systems at Sandia's PSEL have been examined to evaluate the extent of this problem. Figure 10 illustrates a similar problem on much larger system. This figure indicates that this system is at around a 400Ah deficit. The battery in this system is $2600 \mathrm{Ah}$ sealed unit, so 400Ah low is about $85 \%$ state of charge. The charge regulator on this system functions similarly to an "on-off" type but switches from full array current of about 45 amps to a continuous trickle charge of 2.6 amps once the float voltage of 14.1 volts has been acheived. If the load is such that the voltage drops below a certain threshhold, the controller returns to the bulk charging mode until float voltage is attained again. I is believed that this battery began the teating in a rate of full charge because the array had been connected to the battery with no load for several weeks prior to beginning this test, which allowed continual float charging.

Figure 11 illustrates a system similar in all respects to the system represented by figure 7, except the charge regulator is the "constant-voltage" type. With this type regulator, full array current is impressed on the battery until the high-voltage setpoint of 14.2 volts is reached. At this point, instead of disconnecting the array, this type regulator reduces the current to whatever is necessary to maintain the battery voltage at the regulation setpoint. Thus a daily pattern of high current followed by reduced current is established with no "off" time. It can be seen that this battery shows a daily increase of roughly 2 amp-hours. Since this battery began the test in a fully-charged condition, it is assumed that the $2 \mathrm{Ah}$ per day are the losses associated with the battery's round trip energy efficiency-in this case about $10 \%$ losses.

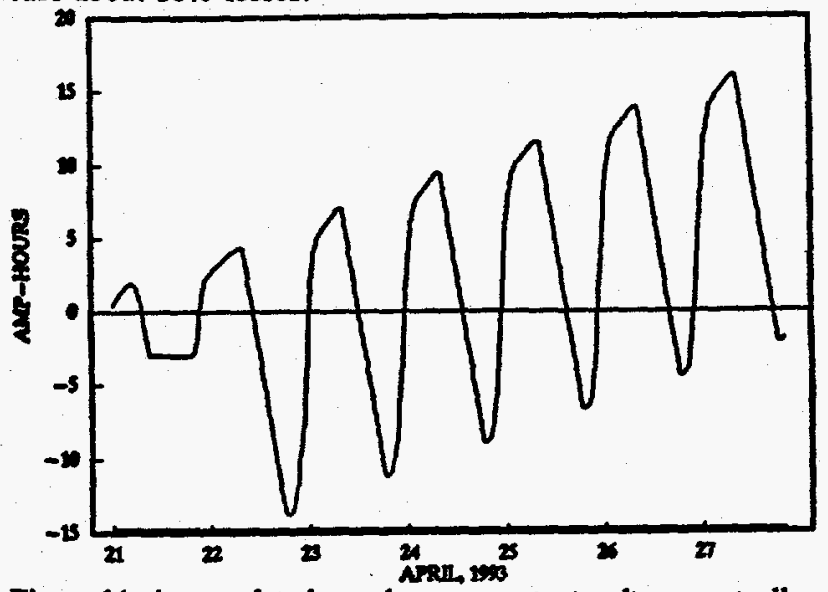

Figure 11. Accumulated amp-hours, constant-voltage controller, 1 battery system. Note that the battery is being maintained in an excellent state of charge.

\section{CONCLUSIONS AND FUTURE WORK}

A recent survey performed by Sandia and the Southwest Technology Development Institute [2] indicated that over $80 \%$ of the charge controllers used in PV systems are on-off controllers. The work described in this paper makes it clear that this type of controller, when applied in a system with a battery to array ratio similar to that in the one-battery system and with 14.5 volt setpoint, limits the ability of the PV system to perform as designed. This can lead to inadequate battery charging, failure to maintain load for the designed days of autonomy and premature battery failure. The impacts on PV aystem design are clear.

- Assumptions about days of autonomy may be invalid.

- Assumptions about battery atate of charge given an array output may be invalid.

- Errors in identifying resource will be compounded.

In order to make better use of charge controllers, the PV system designer needs an understanding of how the controller impacts the battery/array combination. This work has revealed initial information in this area. These relations are in need of more detailed examination. This will include establishing a set of guidelines on battery capacity to array current ratios that will work with on-off controllers for several types of batteries as well as undentanding the setpoints necessary for full charging. This can be extablished by a comprehensive set of charging curves, such as shown in figure 9, for a variety of battery types and tont voltages. Such a set of curves will identify the charging characteristics of families of battery types, allowing the designer to anticipate a battery's ability to accept charge from a given size array. This work is beginning at Sandia's PSEL and is being coordinated with the PV, battery and controller industries. In addition, an understanding of the abilities of the constant-voltage controller, as shown in figure 11, under a 
variety of conditions is being examined.

\section{ACKNOWLEDGEMENTS}

The authors extend their appreciation to Jeff Zirzow for assistance in data management, particularly the data monitoring, reduction and presentation material for the $2600 \mathrm{Ah}$ sealed battery system illustrated in figure 10. We also thank Mike Thomas for his willingness to share the anguish of the "theory of the day" period where what was happening to the batteries was apparent, but why was not. Mike's comments were invaluable in directing the testing in the right area.

\section{REFERENCES}

[1] H.A. Kiehne, Battery Technology Handbook, Marcel Dekker, Inc, 1989.

[2] M. Thomas, S. Harrington, R.L. Hammond, "Photovoltaic Industry Battery Survey", Southwest Technology Development Institute, 93-101-RES, April, 1993. 